\title{
Significados do vivido pela pessoa idosa longeva no processo de morte/morrer e luto
}

\author{
Significances of the life experience for the long-lived elderly person \\ in the process of death/dying and mourning
}

Tânia Maria de Oliva Menezes ${ }^{1}$

Regina Lúcia Mendonça Lopes ${ }^{1}$

${ }^{1}$ Departamento de Enfermagem MédicoCirúrgica e Administração em Enfermagem, Escola de Enfermagem,Universidade Federal da Bahia. R. Augusto Viana s/n, Canela. 40.110060 Salvador BA Brasil. tomenezes50@gmail.com

\begin{abstract}
This is a study using the Heideggerian theoretical-phenomenological approach, which sought to understand the significances of the life experience for the long-lived elderly person in the process of death/dying and mourning. It was conducted in 2009 with 16 long-lived senior citizens of both genders who were aged between 80 and 90, members of a community center for the elderly located in a suburban neighborhood of the city of Salvador in the state of Bahia, Brazil. The results showed that the long-lived elderly person experiences the mourning status process when relatives and friends become ill and die. Furthermore, they gave ambiguous reports with respect to the fear of death. With the attributed significances, it was possible to arrive at the unit of significance, namely the authenticity and lack of authenticity of the individual regarding imminent death. The conclusion reached is that long-lived elderly individuals faced with the process of death/dying and mourning is apparent or concealed in accordance with the moment they are experiencing and the opportunities that present themselves, in other words, it is greatly influenced by their past.
\end{abstract}

Key words People aged 80 or over, Aging process, Death, Grief
Resumo Estudo de abordagem teórico-fenomenológica heideggeriana, que objetivou compreender os significados do vivido pela pessoa idosa longeva no processo de morte/morrer e luto. Realizado em 2009, com 16 idosos longevos, de ambos os sexos, com idade compreendida entre 80 e 90 anos, integrantes de um centro de convivência para idoso localizado em um bairro periférico da cidade de Salvador - Bahia, Brasil. Os resultados evidenciaram que a pessoa idosa longeva vivencia o luto quando pessoas próximas começam a adoecer e morrer. Além disso, apresentaram discurso ambíguo quanto ao medo da morte. Com os significados atribuídos, foi possivel chegar à unidade de significação: a autenticidade e a inautenticidade do ser para a morte. Conclui-se que a pessoa idosa longeva frente ao processo de morte/morrer e luto desvela-se e vela-se de acordo com o momento que ela vive e as oportunidades que se apresentam, ou seja, é muito influenciada por sua historicidade.

Palavras-chave Idoso de 80 anos ou mais, Envelhecimento, Morte, Pesar 


\section{Introdução}

Nas últimas seis décadas, a população brasileira acima de 60 anos tem aumentado significativamente. Essa população irá mais que triplicar nas próximas quatro décadas, de menos de 20 milhões em 2010, para aproximadamente 65 milhões em $2050^{1}$. Dentre as transformações ocorridas no decorrer do século XX, destaca-se a mudança no perfil de morbidade e mortalidade da população, o que resultou num crescimento no número de pessoas idosas e, em especial, no segmento que se encontra acima dos 80 anos de idade, alterando a composição interna do próprio grupo ${ }^{2}$. Em 2050, esse grupo etário deverá corresponder a 19\% da população brasileira ${ }^{3}$.

No imaginário social, o envelhecimento é um processo que se desenrola com desgaste, limitações crescentes e perdas físicas e de papéis sociais, em trajetória que finda com a morte. $\mathrm{O}$ homem admite a morte como um fato, porém, apresenta grande dificuldade em assumi-la como um modo de ser da natureza humana ${ }^{4}$. No tocante ao processo de envelhecer, percebe-se que, ao rejeitar a morte como rejeita, recusando-a com todas as suas forças, o ser humano tende a rejeitar também a velhice, talvez por esta fase da vida ser a que mais se aproxima da morte e, assim, torna a velhice um peso para sua vida ${ }^{5}$.

O idoso se percebe na sucessão de perdas de capacidades e confronta a sua atualidade psicossocial de ser idoso. A velhice, ao se traduzir no contexto social como negatividade, agrava no idoso o que é sentido como perda e fragiliza os seus recursos internos construídos ao longo de toda a vida ${ }^{6-8}$.

A morte não costuma ser vista como algo espontâneo e natural pelas pessoas. Acredita-se que a morte é vivida simbolicamente nas perdas vivenciadas na velhice. Ao lidar com essas perdas, $\mathrm{o}$ idoso lida inevitavelmente com a morte e vivencia o processo de luto?

O morrer, além de ser um processo biológico, apresenta-se como uma construção social. Dessa forma, o processo do morrer pode ser vivido de distintas maneiras, de acordo com os significados compartilhados por esta experiência, uma vez que, esses significados são influenciados pelo momento histórico e pelos contextos sócio-culturais. Nesse sentido, é importante conceber a morte como um processo e não como um fim ${ }^{8}$.

Na prática profissional, atuando com a pessoa idosa em diferentes unidades, seja ela hospitalar, centro de convivência, domicílio e/ou instituição de longa permanência para idosos, percebe-se que estes têm dificuldades em lidar com a temática da morte, principalmente por conta da idade e dos amigos que vão morrendo. Diante dessas considerações, surgiu a inquietação sobre como a pessoa idosa longeva vivencia o processo de morte/morrer e luto no seu cotidiano.

Nesse contexto, o artigo objetiva compreender os significados do vivido pela pessoa idosa no processo de morte/morrer e luto.

\section{Métodos}

Pesquisa qualitativa, com abordagem fenomenológica e referencial teórico-metodológico de Martin Heidegger. A fenomenologia busca desvelar o objeto de estudo, não apenas o que é o fato, mas como o fenômeno é em seus significados e sentidos? .

Os sujeitos da pesquisa integram um centro de convivência para idosos que está localizado em um bairro periférico na cidade de Salvador (BA). Este centro tem 130 idosos inscritos, com uma frequência média de 80 idosos nas atividades que se desenvolvem durante os dias de terça e quintafeira. Como critérios de inclusão foram utilizados: idade igual ou superior a 80 anos e que apresentassem possibilidade de estabelecer um processo de comunicação verbal. Após realizar um período de ambientação com duração de três meses, iniciouse a coleta de dados e o encerramento ocorreu em fevereiro de 2009.

O pesquisador realizou algumas atividades educativas e de sensibilização com o grupo, para posteriormente identificar o idoso de 80 anos ou mais. A partir daí, por meio de uma conversa informal, foi feito o convite para participação do estudo, sendo acordada a data, a hora e o local para a realização do encontro fenomenológico. Todas as entrevistas foram gravadas em aparelho MP3.

Fizeram parte da pesquisa 16 idosos, sendo 12 mulheres e quatro homens, com idade compreendida entre 80 e 90 anos. Para manutenção do anonimato dos sujeitos foi atribuído nome fictício de flores. O projeto foi aprovado pelo Comitê de Ética em Pesquisa da Secretaria de Saúde do Estado da Bahia (SESAB). A técnica empregada para a obtenção dos significados compreendeu a entrevista fenomenológica dos integrantes do estudo, guiada pela seguinte questão: Como o senhor (a) tem vivido o seu envelhecimento até os dias atuais?

Após as transcrições dos depoimentos captados, as falas foram ouvidas várias vezes para $\mathrm{o}$ desenvolvimento do primeiro momento metódico heideggeriano, que é a compreensão vaga e mediana, a instância ôntica. É tudo que surge de imediato a consciência do ser. Depois de destacar 
as estruturas essenciais dos depoimentos, foi possível construir a compreensão dos depoentes em seu conjunto sobre os significados do vivido pela pessoa idosa longeva no processo de morte/morrer e luto. Essa etapa metodológica é a descrição da compreensão de como o idoso de 80 anos ou mais refletiu, significou e se comportou no cotidiano vivido neste processo.

O segundo momento é denominado de hermenêutica. Representa o movimento interpretativo que desvela o (s) sentido (s) do ser que se mostra a partir da compreensão vaga e mediana, é a instância ontológica. Assim, foi destacada a unidade de significação: a autenticidade e inautenticidade do ser para a morte.

\section{Resultados e discussão}

O envelhecimento humano se processa pela ação do tempo cronológico sobre os indivíduos. Este tempo se apresenta como finito ou infinito. $\mathrm{O}$ tempo individual da vida de cada um é finito, quando se esgota na morte biológica. O tempo infinito é aquele subjetivado nas possibilidades de produzir eternidades que cada imaginário possui.

O homem existe para morrer, assim, ao ser autêntico é permitida a aceitação da sua possibilidade mais própria, a sua morte. Apesar de, em nosso cotidiano, a morte ser uma contínua fuga, o certo é que ela há de vir. É evidente que, com o passar da idade, qualquer indivíduo se defronta com a possibilidade da morte, com a diminuição real de suas perspectivas e com os efeitos que isso produz na sua relação com o passado.

Nesse sentido, a morte é uma das dimensões existenciais do homem. É tratada como possibilidade de ser da presença, a partir da situação de ser lançado como ser-para-a-morte, como também a possibilidade mais própria da presença. $\mathrm{O}$ ser, para essa possibilidade, abre a presença o seu poder ser mais próprio, em que sempre está em jogo o próprio ser da presença a qual revela o ser para o fim ${ }^{9}$.

A temporalidade originária foi liberada a partir da presença decidida antecipadamente, partindo de uma referência originária à morte. $\mathrm{O}$ que marca a temporalidade é o ser-para-a-morte. A morte é a possibilidade mais própria de cada um, por isso, somos ser para a morte. A morte pertence, num sentido privilegiado, ao ser da presença ${ }^{9}$. Esclarece-se o conceito existencial da morte como ser lançado para o poder-ser mais próprio, irremissível e insuperável ${ }^{9}$. Só posso viver a minha morte antecipadamente, o que desencadeia o medo e a fuga, conforme os relatos a seguir:
Eu sou muito medrosa. Eu tenho medo de morrer. E tem horas que, quando eu me lembro! Estou passando o tempo e uns amigos morreram, daqui a pouco sou eu. Ninguém pode fugir, de jeito nenhum (Jasmim).

Eu não vou dizer que quando eu estou triste é que eu falo na morte. Porque não ter morrido já com essa idade é tudo, não é? (Violeta).

Parece haver um acordo geral em negar a morte, não possibilitando, assim, uma transição psicológica e ritos de passagem para ajudar o que sofre a perda. Nesse sentido, a negação da morte surge como uma fuga que desloca esse acontecimento para bem longe, levando a uma falsa sensação de imortalidade $^{10}$.

A morte é ontológica porque coloca a antecipação e esta nos permite experimentar a temporalidade. Antecipar a morte é sempre realizar possibilidades. Percebemos que somos temporalidade no 'ser para a morte', que expressa o caráter de antecipação da presença, assim como evidenciado nas linguagens que se seguem:

Sentir que a morte está chegando, sinto (Rosa).

E aí, eu estou pedindo a Deus que eu chegue aos 90, pelo menos, pelo menos aos noventa anos de idade (Girassol).

A investigação a respeito da morte se fundamenta na possibilidade da presença 'ser toda', isto é, ser enquanto uma totalidade existencial plena, que abarque tanto seu início quanto o seu fim. 'Ser todo', ser enquanto totalidade, não significa ser sob o modo da infinitude, ser infinito. Ao contrário, só é possível a presença 'ser toda' com base em uma fronteira que determine o alcance de sua totalidade. Portanto, o 'ser todo’ pressupõe a existência de um fim, e este fim é a morte'.

O Homem é visto como 'ser aî' ou Dasein, que significa, necessariamente, um 'ser no mundo,' 'ser consigo mesmo' e com o outro, que interroga a si mesmo em busca de sua verdade. O 'ser só' pode ser determinado a partir de seu sentido como ele mesmo, ou seja, a compreensão do 'ser' somente é possível no contexto de seu próprio mundo, suas experiências e vivências? .

Além da característica de 'ser no mundo', o 'ser aî' é um 'ser para a morte’. A existência não é dada ao homem como um caminho bem arranjado ao fim do qual está a morte, mas a morte como possibilidade pode atravessar sua existência a qualquer momento. A morte é entendida como a possibilidade inalienável de poder não mais estar presente, uma possibilidade ontológica que o Dasein tem que assumir; com ela, o 'ser aî' completa o seu curso9.

O fim de um ente, enquanto presença, é o seu princípio como mero ser simplesmente dado ${ }^{9}$. 
Assim, a morte não é o fim, pois ela está sempre lançada como possibilidade. O ser para a possibilidade enquanto 'ser para a morte', no entanto, deve relacionar-se para com a morte de tal modo que ela se desvele nesse ser e para ele como possibilidade?.

Nesse sentido, o 'ser para a morte' pode ser autêntico ou inautêntico. Na autenticidade, encontramos o atentar para a morte como possibilidade mais própria, que diz respeito ao 'poder ser' do 'ser aí. A esse respeito, a possibilidade mais própria é irremissível. O antecipar permite a presença compreender que o 'poder ser', no qual o que está em jogo é o seu próprio ser, só pode ser assumido por ela mesma. A morte não apenas pertence de forma não indiferente à própria presença, como reivindica a presença ${ }^{9}$. Na morte, a presença também é 'poder ser'. Diz-se que a morte é certa e, com isso, implanta-se na presença, a aparência de que se está em si mesmo certo da morte?

No cotidiano da pessoa idosa longeva, a morte está sempre presente e retratada como uma certe$\mathrm{za}$, conforme os relatos abaixo:

Eu não quero nada de coisa, porque a gente não vai ficar aqui a vida toda! Um dia tem que ir, não é? (Angélica).

Se chegar meu dia, todo mundo tem que morrer, né? (Hortênsia).

Tem que morrer, né? (Jasmim).

Mas, eu estou pensando, amanhã ou depois, eu com essa idade, né? Posso passar mal, morrer (Lírio).

As falas revelam que os idosos têm a morte como uma certeza, já que não se vai ficar aqui a vida toda. Durante as entrevistas, esta certeza não se traduziu com pesar, mas com tranquilidade. Além disso, a morte se apresenta como possibilidade para eles.

'Ser para a morte', em sentido próprio, não pode escapar da possibilidade mais própria e irremissível e, nessa fuga, encobri-la e alterar o seu sentido em favor da compreensão do impessoal ${ }^{9}$.

A morte é uma das dimensões existenciais do homem. Só podemos ter a vivência da nossa própria morte e nunca da morte do outro. Logo, antecipando a possibilidade da morte, através do ekstase finito do porvir, a presença vem a si mesma e é relançada sobre sua facticidade, isto é, reconduzida às possibilidades de fato que são as suas, e ele encontra aí com seu mundo de fato9.

$\mathrm{O}$ 'ter por verdadeira' a morte mostra outro modo de certeza, sendo mais originário com relação à certeza referente a um ente que vem ao encontro dentro do mundo ou aos objetos formais; trata-se do 'estar certo' de 'ser no mundo'.

A presença cotidiana encobre, na maior parte das vezes, a possibilidade mais própria, irremissível e insuperável de seu ser. Sendo assim, a morte e o 'ser para o fim' na cotidianidade são mostrados de maneira imprópria e a angústia é transformada no temor de deixar de viver' ${ }^{9}$. Encarar a morte como parte da vida é algo rejeitado pela consciência ${ }^{11}$. Essa é a forma inautêntica de existir do Dasein, na qual ele se envolve com as ocupações cotidianas e é absorvido pelas preocupações. As ocupações e preocupações fazem com que o homem fuja a sua condição de 'ser no mundo'.

Pode ser que a privação da saúde, o padecimento, forneça ocasião para que se abra a potencialidade do modo próprio, autêntico. É o que se denomina de reatamento do Dasein no seu 'ser no mundo'12.

O reatamento é o encontro do Dasein com sua potencialidade de ser própria, que se forma como projeto antevisto no modo do padecimento e no angustiar-se verdadeiro com sua própria existência, na perspectiva segura da possibilidade da morte ${ }^{12}$.

A morte é tomada para si pela presença, na disposição da angústia, revelando-a de forma originária e profunda. A angústia cresce a partir do 'ser no mundo' enquanto 'ser lançado para a morte".

$\mathrm{Na}$ angústia, não sabemos diante de que nos angustiamos. Ela tem início quando em meio as nossas ocupações do cotidiano, nos aparece certo tédio. Quando a presença fica angustiada, ela retoma, repensa e pode transcender ou não, de acordo com a sua decisão.

A angústia não é vista somente como um fenômeno psicológico e ôntico, ou seja, que se refere somente a um ente ou algo dado, e sim, sua dimensão é ontológica, pois nos remete à totalidade da existência como 'ser no mundo's. É por meio da angústia, estrutura fundamental, que dá condição ao Dasein rumar à autenticidade e que este pode se livrar do peso imposto pelo cotidiano, conforme a fala abaixo:

Eu fico em casa o dia todo sozinha. Quando chega a noite, eu não tenho ninguém para conversar, a não ser televisão. Então nessa hora me bate uma angústia e choro e peço a Deus que me tire essa angústia (Rosa).

Existe uma diferença entre angústia e temor, sendo que a primeira é mais ampla. O temor é um existente fundamental, mediante o qual o homem se encontra no mundo. O fenômeno do temor é analisado em três perspectivas: o que se teme, o temer e pelo que se teme'. O de que se teme, $\mathrm{o}$ amedrontador, é sempre um ente que vem ao encontro dentro do mundo e que possui o modo de ser do que está a mão, ou do ser simplesmente dado, ou 
ainda, da co-presença ${ }^{9}$. O que a pessoa idosa longeva teme, em algumas situações, é a doença e a morte, que faz parte da vida e que encerra as possibilidades de 'ser aí', conforme expresso na fala a seguir:

Porque o câncer é uma dessas doenças que é difícil, muito difícil. Todo mundo tem medo, não gosta nem de falar (Rosa).

No temor surge o medo. O medo é uma disposição na nossa existência pelo fato de que ela manifesta o mundo no ato de fuga do 'ser aí' de si mesmo. A esse respeito, refere que o medo vela, ao mesmo tempo, o estar e 'ser em' perigo, já que deixa ver em perigo a ponto de a presença precisar se recompor depois que ele passa. Ter medo por ou ter medo de alguma coisa sempre abre, de modo igualmente originário, o ente intramundano em sua possibilidade de ameaçar e o 'ser em' no tocante ao estar ameaçado?.

Nesse estudo, os idosos expressaram em seus depoimentos ambiguidade no tocante ao medo da morte. As falas abaixo expressam que eles não têm medo da morte:

Então, não tenho medo da morte, não. Quando eles quiserem me-tirar, quando me-levar pro outro mundo deles, oxente! (Angélica).

Eu penso na morte, mas sem medo. Eu penso sem medo mesmo (Violeta).

Eu não tenho medo de morrer. Eu só tenho medo de eles me enterrarem viva (Rosa).

É, porém, aproximando-se na proximidade que o prejudicial ameaça, pois pode chegar ou não9 ${ }^{9}$ A consciência da finitude parece levar os idosos a uma maior aproximação com a ideia de morte e, consequente, aceitação desta etapa como inevitável ${ }^{13}$. Assim, alguns idosos fizeram referências ao medo da morte, conforme o relato abaixo:

Eu sou muito medrosa. Eu tenho medo de morrer. E tem horas que me lembro que alguns amigos já morreram, daqui a pouco sou eu (Jasmim).

Eu vi vários colegas morrerem (Girassol).

Não acredito que ninguém vá dizer assim, eu não tenho medo da morte, não. O medo da morte é normal em qualquer ser humano (Rosa).

O medo não apenas se relaciona com o que está por vir, entendido como o que só advém no tempo, mas também esse relaciona-se em si mesmo, no já está por vir, no sentido do tempo originário9. O ter medo, ele mesmo libera a ameaça que assim caracterizada se deixa e faz tocar a si mesma9.

Na convivência da publicidade, a morte é reconhecida como fato comum e mais distante, embora aconteça diariamente. Diz-se que a morte certamente vem, mas por ora ainda não. A morte é algo que vem ao encontro do outro, que não sou eu, mas é ninguém ${ }^{9}$.
Nesse sentido, refere que a presença encobre para si mesma o 'ser para a morte' mais próprio em dele fugindo. É existindo que a presença morre de fato, embora, numa primeira aproximação e na maior parte das vazes, o faça no modo da decadência ${ }^{9}$. Assim sendo, embora se apresente na perspectiva do que se teme, é tratada de modo indiferente, como um acontecimento público, porém ameaçador.

Eu vejo os amigos morrendo, daqui a pouco sou eu (Cravo).

O teor público da convivência cotidiana conhece a morte como uma ocorrência que sempre vem ao encontro, ou seja, como casos de morte. A morte vem ao encontro como um acontecimento conhecido, que ocorre dentro do mundo?.

$\mathrm{Na}$ prática verificou-se que o idoso longevo mantém um discurso ambíguo no tocante à morte/morrer. Na linguagem dos sujeitos, a morte é percebida, mas não é reconhecida, na maioria das vezes, como possibilidade mais própria da presença, ocorrendo a fuga e o encobrimento dessa condição, pois no seu cotidiano, a presença se volta para as ocupações mundanas, a fim de não refletir a única certeza da vida.

Eu não estou querendo morrer agora. Ainda quero viver. Todo o dia, eu peço a Deus que ele me dê ainda mais uns tempos de vida. Mas, se chegaro dia eu não tenho medo não (Hortênsia).

Mas, que nada doutor. Será que eu vou morrer agora? Não. Eu ainda tenho muito tempo pra frente. Eu digo, bom, eu pretendo morrer com 110 anos (risos). Porque, na hora que eu pensar em morrer, eu acho que demora muito tempo (Dália).

A não-aceitação desse processo como parte do ciclo de vida tem relação com o medo do desconhecido, uma vez que ninguém sabe o que acontece após a morte ${ }^{8}$. De outra maneira, a pessoa idosa longeva pensa na morte, mas foge do tema conforme discurso de Graxa:

Meu marido morreu primeiro. Há 25 anos morreu meu filho. Eu penso na morte sim, mas, eu não gosto de falar sobre isso. Um filho já rapaz, isso não dói? (Graxa).

Graxa não consegue esquecer o falecimento do filho, que se deu por acidente de carro ainda jovem. Apesar de ela dizer que não gosta de falar sobre isso, em outras oportunidades de diálogo com a mesma no grupo de convivência, ela traz o assunto para conversar, repetindo sempre os mesmos fatos. Isso significa que não elaborou o luto.

Devemos considerar o impacto da morte de um filho no idoso como capaz de suscitar o sentimento de culpa por estar sobrevivendo ao filho, agravado pela dificuldade em trabalhar 
emocionalmente a morte, somada a tantas outras dificuldades presentes, decorrentes de alterações físicas e isolamento social. No processo de luto, quanto maior o investimento afetivo, maior será a energia para o desligamento ${ }^{12}$.

O luto, como não é um processo linear, não tem data para terminar, podendo durar meses e anos, ou mesmo nunca acabar, na dependência direta das características individuais da personalidade e ainda do nível e intensidade de relação que se manteve com o falecido ${ }^{11}$.

O impessoal encobre o que há de característico na certeza da morte, ou seja, que é possível a todo o instante ${ }^{9}$. A fuga também é percebida na fala de Dália, quando diz que pretende morrer com 110 anos.

Com a fuga decadente da morte, porém, a continuidade da presença também atesta que o próprio impessoal, mesmo quando não está explicitamente pensando na morte, já está sempre se determinando como 'ser para a morte'.

A explicação do 'ser para a morte' cotidiano deteve-se na falação do impessoal: algum dia se morre, mas, por ora ainda não ${ }^{9}$. Para alguns idosos, a morte ainda está distante, porque eles ainda têm projetos que desejam por em prática, fazendo referências a filhos e netos.

Eu não quero morrer agora, porque eu tenho muito filho pra eu reparar. Eu tenho muito neto pra eu reparar. E pra eu morrer agora, já não morro muito tranquila (Dália).

Embora "traumatizados" pela morte e pela perda de pessoas queridas, os homens vivem como se nunca fossem realmente morrer ${ }^{7}$. Ainda sobre outro aspecto, a morte é um modo de ser que a presença assume no momento que é. Para morrer, basta estar vivo9. O finar é o findar do ser vivo, refere-se ao biológico. A presença também possui uma morte fisiológica, própria da vida ${ }^{9}$. Assim, o idoso também percebe a proximidade da morte, referindo à necessidade de se preparar para isso,

Eu já disse a minha filha. Eu vou fazer minha mortalha. Ele vai me-dar esse poder, porque eu quero morrer, eu quero ir no caixão bem bonitinha, toda enfeitada de flores (Angélica).

Eu vou ser sincero. Eu, às vezes, eu penso. Eu digo, poxa, estou chegando numa idade! Eu vou me-preparar pra morrer. Não quero que meus parentes tenham essa, esses compromissos de pagar meu enterro, não (Lírio).

É tendo medo que o medo pode ter claro para si o de que tem medo, esclarecendo-o ${ }^{9}$. Na convivência cotidiana, o encobrimento e a fuga da morte tranquilizam a presença, retirando da certeza da morte, a sua possibilidade constante e intransponível, ou seja, o fato de ser indeterminada.
A morte também é vista como perda. $\mathrm{Na}$ experiência da pessoa idosa ver que os seus amigos e familiares estão partindo, lhes configura como a proximidade da própria morte e da perda, o que faz voltar seus pensamentos para a morte, conforme os depoimentos abaixo:

Eu tive duas irmãs gêmeas. Morreram novas. Só tem eu e o Cravo agora. Aí, eu tive pensando nessas coisas (Lírio).

E todos os colegas meus, os amigos, colega de repartição, coisa e tal, que tiveram mexendo nessa doença de próstata, a maioria deles morreram. Eu fiquei sentido deles morrerem. Eu vou numerar, uns cinco a seis que morreram (Girassol).

E tem horas que, quando eu me lembro, ah, meu Deus! Estou passando o tempo, e uns amigos morreram, daqui a pouco sou eu. Ninguém pode fugir, de jeito nenhum (Jasmim).

A morte se desvela como perda e, mais do que isso, como aquela perda experimentada pelos que ficam. [...] não fazemos a experiência da morte dos outros. No máximo, estamos apenas junto ${ }^{9}$. O processo de morrer e a morte do outro despertam sentimentos de medo, raiva, impotência, insegurança, estando mais relacionado à perda e à separação do que a um processo natural da vida ${ }^{8}$.

A nossa primeira abordagem objetiva do fenômeno da morte ocorre através da morte de outros, porém, por mais vivida que seja a nossa apreensão da morte de outros, não podemos ter a experiência, não podemos tomar parte nesse 'chegar a um fim'. A pessoa idosa longeva vivencia a morte diante das perdas que vão se acentuando com o processo de envelhecimento.

Diante de tais considerações, foi possível compreender que o processo de morte e morrer na dimensão ôntica faz parte do existir desde quando nascemos. Morrer é a possibilidade mais extrema do idoso, pois põe em jogo o seu 'ser no mundo'. Sendo assim, não há como escapar da possibilidade mais original da existência, que é não mais existir. No ontológico, o morrer vem significar o encerramento de um modo de ser, para a abertura de novas possibilidades ou novos modos de ser.

A pessoa idosa longeva apresenta sentimentos variados com a morte do outro, provocação da ruptura do vínculo amoroso que o unia aquela pessoa que lhe dava alegria de viver. Este fato leva a percepção de aproximação da própria morte, quando vê que parentes e amigos estão morrendo.

A pesquisa permitiu compreender que a pessoa idosa longeva frente ao processo de morte/ morrer e luto desvela-se e vela-se, de acordo com o momento que ele vive, as oportunidades que se apresentam, muito influenciado por sua historicidade. Apesar do temor, angústia e medo 
que a morte/morrer e luto ocasionam no vivido da pessoa idosa, ela abre possibilidade de dar um sentido pleno à existência, que se apresenta com perdas nos aspectos bio-psico-social-cultural.

Nesse contexto, torna-se fundamental o investimento em ações educativas para a população em geral, bem como para a pessoa idosa, de forma a contribuir para desmistificar o estereótipo de que chegar a esta idade significa caminhar lado a lado com a morte. Ainda há muito o que fazer, aprender e ser.

\section{Colaboradores}

TMO Menezes trabalhou na concepção da pesquisa, metodologia, pesquisa de campo, análise, discussão e redação final do artigo e RLM Lopes na análise e orientação da pesquisa. 


\section{Referências}

1. Banco Mundial. Population aging: is Latin America rea$d y$ ? Directions in development. Washington: The World Bank; 2011.

2. Oliveira LPBA, Menezes RMP. Representações de fragilidade para idosos no contexto da estratégia de saúde da família. Texto Contexto Enfermagem 2011;20(2):301-309.

3. Nasri F. O envelhecimento populacional brasileiro. Einstein 2008; 6(Supl.):S4-S6.

4. Frumi C, Celich KLS. O olhar do idoso frente o envelhecimento e à morte. Revista Brasileira de Ciências do Envelhecimento Humano 2006; 3(2):92-100.

5. Santos SSC. Concepções teórico-filosóficas sobre envelhecimento, velhice, idoso e enfermagem gerontogeriátrica. Revista Brasileira de Enfermagem 2010; 63(6):1035-1039.

6. Py L, Oliveira JFPA. À espera do nada. Cien Saude Colet 2012; 17(8):1957-1959.

7. Cocentino JMB, Viana TC. A velhice e a morte: reflexões sobre o processo de luto. Rev Bras Geriatr Gerontol 2011; 14(3):591-599.

8. Fratezi FR, Gutierez BAO. Cuidador familiar do idoso em cuidados paliativos: o processo de morrer em domicilio. Cienc Saude Colet 2011; 17(8):3241-3248.

9. Heidegger M. Ser e Tempo. Rio de Janeiro (RJ): Vozes; 2006.

10. Borges ADVS, Silva EF, Toniollo PB, Mazer SM, Valle ERM, Santos MA. Percepção da morte pelo paciente oncológico ao longo do desenvolvimento. Psicologia em estudo 2006; 11(2):361-369.

11. Nogueira RP. Extensão fenomenológica dos conceitos de saúde e enfermidade em Heidegger. Cien Saude Colet 2011; 16(1):259-266.

12. Oliveira JBA, Lopes RGC. O processo de luto no idoso pela morte de cônjuge e filho. RBCEH - Revista Brasileira de Ciências do Envelhecimento Humano 2006; 13(2):92-100.

13. Barbosa CG, Melchiori LE, Neme CMB. O significado da morte para adolescentes, adultos e idosos. Paidéia 2011; 21(49):175-185.

Artigo apresentado em 29/04/2013

Aprovado em 23/07/2013

Versão final apresentada em 29/07/2013 